\title{
Weaver Mouse Cerebellar Granule Neurons Fail to Migrate on Wild-Type Astroglial Processes in vitro
}

\author{
M. E. Hatten, R. K. H. Liem, and C. A. Mason \\ Department of Pharmacology, New York University Medical Center, New York, NY 10016
}

To study the regulation of glial-guided neuronal migration, we have analyzed the behavior of cerebellar granule neurons purified from the homozygous weaver ( $w v / w v$ ) B6CBA-w mouse, an autosomal recessive genetic mutation that suffers a failure of granule cell migration along Bergmann glial processes (Rakic and Sidman, 1973a, b; Rezai and Yoon, 1972), on the processes of astroglia purified from homozygous normal B6CBA-A ${ }^{w-J}-w v$ $(+/ t)$ mouse cerebella.

When co-cultured with normal astroglia, weaver granule neurons failed to form neuron-glia contacts characteristic of migrating neurons and impaired normal astroglial morphological differentiation. Normal astroglial cells co-cultured with weaver granule cells had enlarged cell somata with stunted processes and enlarged endfeet compared to normal astroglia co-cultured with normal granule cells. In contrast, normal neurons associated with weaver astroglia, forming tight appositions seen for migrating neurons in vivo, and enhanced weaver astroglial morphological differentiation. Weaver astroglia co-cultured with normal granule cells contained a more normal complement of glial filaments and had a smaller perikaryon with longer, more tapered processes than their counterparts co-cultured with weaver neurons.

These results suggest, in agreement with the study of Goldowitz and Mullen (1982) on heterozygous mutant chimeras, that the granule neuron is a primary site of action of the weaver gene, and further support our previous findings that neuron-glia interactions regulate astroglial morphological differentiation (Hatten, 1985).

In many regions of the developing mammalian brain, young neurons migrate from their site of origin to their proper cortical position by scaling the processes of astroglial cells (Sidman and Rakic, 1978). The weaver mutant mouse has been used to test the glial-guidance paradigm because weaver cerebellar granule neurons fail to migrate and die in ectopic positions (Goldowitz and Mullen, 1982; Rakic and Sidman, 1973a, b; Rezai and Yoon, 1972; Sotelo and Changeaux, 1974). The central issue has been whether the neuron or the glial cell is defective, in either case leading to a failure of migration.

In normal animals, an intimate relationship has been described between granule neurons and Bergmann glia during granule cell migration (Rakic, 1971; Rakic et al., 1974). Granule

\footnotetext{
Received Dec. 23, 1985; revised Feb. 18, 1986; accepted Feb. 21, 1986.

We thank our colleagues Drs. M. L. Shelanski, A. Prochiantz, S. Roffler-Tarlov, and E. Trenkner for their advice, and Ann Francois, Mary Repo, and Margaret Woods for technical assistance. James Edmondson made the photographs, Susan Hutchison prepared the photographic plates, and Julia Cohen kindly typed the manuscript. This work was supported by NIH Grants NS 15429, NS 15182, and NS 21907 . M.E.H. is the recipient of a Sloan Research Fellowship, C.A.M. of a NIH RCDA, and all three authors of an Irma T. Hirschl Career Scientist Award.

Correspondence should be addressed to M. E. Hatten, Department of Pharmacology, New York University School of Medicine, 550 First Avenue, New York, NY 10016.

Copyright @ 1986 Society for Neuroscience $0270-6474 / 86 / 092676-08 \$ 02.00 / 0$
}

cells tightly appose their cell somata against the glial fiber and extend a thickened, leading process down the glial arm in the direction of migration. In vitro, the migration of living cerebellar granule neurons on the processes of Bergmann-like astroglia cells has been visualized in real time with time-lapse video microscopy (Hatten et al., 1984a), and has been found to occur at speeds of $10-50 \mu \mathrm{m} / \mathrm{hr}$ via neuron-glia contacts that closely resemble those seen in vivo (Rakic, 1971; Rakic et al., 1974).

In vitro separation and recombination of neurons and astroglia, made possible by recently developed methods of rapidly purifying cerebellar neurons and astroglia, have shown that neurons profoundly influence glial morphological differentiation and regulate astroglial growth (Hatten, 1985). Recent studies indicate that neuron-glia contacts form very rapidly in vitro, and that glial process outgrowth follows within a few hours (Hatten et al., 1985). In addition, plasma membranes purified from granule neurons inhibit glial proliferation, suggesting that elements of the ncuronal membrane regulate glial proliferation (Hatten et al., 1985).

In the weaver mouse, granule neurons fail to migrate along Bergmann processes and die in ectopic positions. The shape and disposition of astroglial processes is abnormal in weaver, weaver Bergmann cells having enlarged perikarya filled with tangled glial filaments and stunted processes that fail to align in a radial direction (Bignami and Dahl, 1974; Rakic and Sidman, 1973a, b; Rezai and Yoon, 1972; Sotelo and Changeaux, 1974). Thus both the granule neuron and the Bergmann glial cell are abnormal in weaver, raising the question as to which cell is the primary site of action of the weaver gene, a question that relates to the more general issue of which cell, the neuron or the glial cell, directs the cellular relationship needed for neuronal migration.

Several experimental systems have recently been used to analyze the weaver defect. Studies on heterozygous mutant chimeras suggest that the granule neuron is a primary site of action of the weaver gene (Goldowitz and Mullen, 1982). In vitro studies indicate that weaver granule neurons survive poorly, extend shorter neurites, and fail to associate with weaver astroglia (Hatten et al., 1984b; Willinger and Margolis, 1985). Interestingly, weaver neurons do not form the tight appositions to astroglial processes characteristic of migrating granule neurons in vitro (Hatten et al., 1984b) and weaver astroglia have a less differentiated morphology than their normal counterparts, bearing flattened, stunted arms filled with tangled intermediate filaments. A question not yet addressed is whether the defects seen in astroglial cells are intrinsic or relate to the failure of weaver granule cells to induce the morphological differentiation of weaver astroglia.

To test the site of action of the weaver gene, we separated neurons and astroglia from normal and mutant cerebellum (Hatten, 1985) and recombined them in vitro. We then immunostained cells in the recombination cultures with cellular antigen markers for neurons and astroglia (Hatten and Liem, 1981; Hatten et al., 1984a) to compare the interactions of normal 
$(+/+)$ and weaver $(w v / w v)$ neurons with astroglia of different genotypes, especially the ability of weaver neurons to assume a migrating posture on normal astroglia and the influence of normal neurons on weaver astroglial cell morphology.

\section{Materials and Methods}

All studies were carried out with cells from homozygous wild-type B6CBA-A ${ }^{w}-J-w v(+/+)$ or weaver $(w v / w v)$ mice harvested on the third or fourth postnatal day (P3, P4). Weaver $(w v / w v)$ cerebella were identified by their smaller overall dimensions, especially at the midline, and smaller number of folia (Rakic and Sidman, 1973b). Heterozygous animals $(+/ w v)$ were not studied. The most medial third of normal $(+/+)$ or weaver $(w v / w v)$ cerebella on either side of the midline was dissociated into a single cell suspension, as described previously (Hatten and Francois, 1981). Prior to plating, neurons and astroglia were separated into highly purified cell fractions with a step gradient of Percoll followed by a brief preplating on a polylysine-coated culture dish (Hatten, 1985). Cells from 14 litters were analyzed.

The purity of the cell fractions was confirmed as described previously (Hatten, 1985; Hatten et al., 1984a). Cellular antigen markers were used to identify the cell types present in the cultures. Immunostaining with antisera raised against the glial filament protein (AbGFP) (Hatten and Liem, 1981; Hatten et al., 1984a; Liem et al., 1978) was used to identify astroglial cells. Immunostaining with antisera raised against the nerve growth factor-inducible large external protein (NILE) was used to mark neurons (Hatten et al., 1984a; Salton et al., 1983). These antisera were kindly provided by our colleagues, Drs. L. Greene and M. L. Shelanski. In most experiments, immunostaining was by the peroxidase-antiperoxidase method (PAP) (see Hatten et al., 1984a).

In all experiments, the astroglial fraction was completely free of neurons and the neuronal fraction was more than $98 \%$ pure, the maximum number of contaminating astroglia being less than $5 \%$ of the number of astroglia in the culture to which the neurons were to be added. Electron microscopy suggests that the neuronal fraction is overwhelmingly composed of granule neurons (Hatten, 1985).

In each experiment, granule neurons were added to astroglia at plating at a ratio of $4: 1$, the total number of cells in each microculture $(200 \mu \mathrm{l})$ being 1-4 $\times 10^{5}$. As a control for each experiment, cultures of normal $(+/+)$ and weaver $(w v / w v)$ granule neurons and astroglia were made and immunoslained with AbGFP to confirm their purity.

After $48 \mathrm{hr}$ in vitro, the distribution of neurons relative to AbGFPstained astroglia was measured as described by Hatten and Liem (1981), except that values were obtained directly from the microscopic image by projecting it through a drawing tube onto a HIPAD tablet and measuring the distance of each neuron from the nearest stained astroglial process with a Bioquant image analysis system.

The plating efficiency of neurons purified from either normal or weaver cerebella was measured $24 \mathrm{hr}$ after plating (Hatten and Sidman, 1978). The values for normal neurons were $85-95 \%$ when plated on either normal or weaver glia; those of weaver neurons were $20-40 \%$ when plated on normal glia and less than $5 \%$ when plated on weaver glia. All values were for cells harvested from the midline portion of the cerebellum.

In some experiments, the number of surviving weaver neurons was brought to the total number expected for normal granule neurons by increasing the number of cells plated 4-fold.

In previous experiments, we reported that cerebellar granule neurons migrate along the processes of elongated forms of astroglial cells by flattening their cell body against the glial arm and extending a leading process in the direction of migration, a posture that closely resembles neuron-glia relationships seen in vivo (Rakic, 1971). In the present report, neurons that tightly apposed their cell somata to, and extended a leading process along, an AbGFP-stained glial process (see Fig. 3 and Hatten et al., 1984a) were scored as migrating cells from companion cultures with approximately (within 10\%) the same number of astroglia.

\section{Results}

Since the cell separation technique used for these studies generates pure cell populations only when the cells are harvested from early postnatal (days 2-4) cerebellum (Hatten, 1985), we analyzed cells from young weaver and normal animals. At P3 and P4, the weaver cerebellum is slightly reduced in size, but does not yet have a large number of dying granule neurons or debris. The latter is characteristic of the second postnatal week, when a large number of granule cells have failed to migrate and die in ectopic positions (Rakic and Sidman, 1973a, b; Rezai and Yoon, 1972).

When cells dissociated from the midline third of weaver cerebellum were applied to a step gradient of Percoll and preplated onto a polylysine-coated culture dish, the cells were purified into 4 fractions, 2 of which were collected and used for culture studies. The first, the large cell fraction that adhered to polylysine, was a highly purified (more than 99\%) astroglial preparation; the second, from the small cell fraction that did not adhere to polylysine during the preplating step, was a highly purified granule neuron fraction. In cell size, morphology, cellular antigen markers, and electron microscopy, the purity of the fractions approximated that reported for $\mathrm{C} 57 \mathrm{Bl} / 6 \mathrm{~J}$ mouse cerebellum (Hatten, 1985) (not shown). The yield of granule neurons from weaver cerebellum was reduced by $10-20 \%$. The finding that weaver cells could be separated by the same method used for normal cells is probably related to the fact that the cells were harvested at P3 or P4, a week before the onset of severe defects in weaver.

To assay the morphological differentiation and cell-cell interactions of astroglia co-cultured with normal or weaver neurons, we immunostained the cultures with AbGFP. As was reported recently for cells from $\mathrm{C} 57 / \mathrm{Bl6J}$ mouse cerebellum (Hatten, 1985), normal B6CBA-A ${ }^{w}-J-w v(+/+)$ astroglia cultured in the absence of neurons had undifferentiated morphologies with a flattened form, an enlarged cell body in which glial filaments were often arranged in a perinuclear cap, and, when present, stunted processes with grossly thickened endings. None of the cells stained with antisera raised against fibronectin (not shown) (Hatten, 1985), suggesting that they were astroglial and not meningeal in origin.

When normal B6CBA mouse cerebellar neurons were added back to normal astroglia, the glia expressed the differentiated shapes commonly seen in microcultures of $\mathrm{C} 57 \mathrm{Bl} / 6 \mathrm{~J}$ postnatal cerebellar cells and neurons associated with them (not shown) (Hatten, 1985). The vast majority (80-90\%) of AbGFP-stained cells had cell somas $8-10 \mu \mathrm{m}$ in diameter with 6 or more processes $40-60 \mu \mathrm{m}$ in length radiating out from the cell body. The tcrminations of staincd glial processes were tapered. As was seen with mixed cultures of early postnatal $\mathrm{C} 57 \mathrm{Bl} / 6 \mathrm{~J}$ cerebellar cells, these astroglial cells generally harbored 12 or more neurons among their arms. A second glial form was seen as well, resembling Bergmann glia because of its slightly smaller soma and fewer, markedly longer processes $(100-150 \mu \mathrm{m})$. These cells accounted for approximately $10 \%$ of the stained astroglial cells. On the long arms of Bergmann-like astroglia, more than 300 neurons in each microculture had the shape characteristic of migrating neurons-a thickened leading process and an elongated cell soma adhering to the glial process (Table 2) (Hatten et al., 1984a; Rakic and Sidman, 1973a, b).

Purified weaver $(w v / w v)$ astroglia, cultured without neurons, also closely resembled normal astroglia cultured alone (Hatten, 1985) (not shown), with enlarged cell bodies having a flattened shape, few, if any, processes, and glial filaments arranged in a perinuclear cap or in tangles within the cytoplasm.

When weaver neurons were added to weaver astroglia, most of the neurons died within a day of plating, the astroglia failed to differentiate into complex forms that resembled astroglia seen in vivo, and few neuron-glia contacts were seen. These cultures resembled those seen previously from dissociated (mixed) weaver cerebellum (Hatten et al., 1984b).

When weaver neurons were added to normal astroglia, 3 differences were seen from normal neurons and normal astroglia. First, the plating efficiency of weaver neurons was lower than 


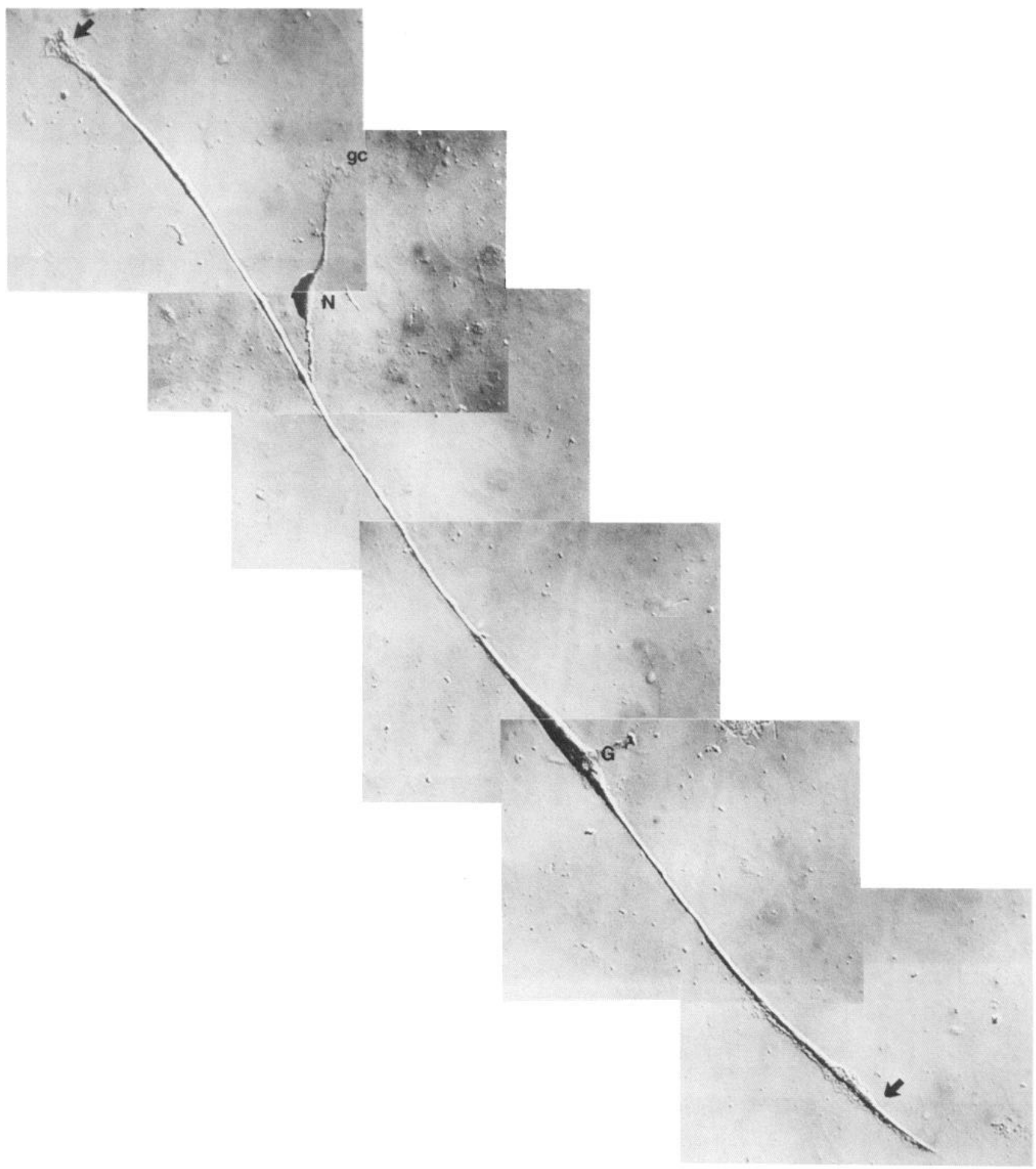

Figure 1. Interaction of $\mathrm{P} 4$ weaver $(w v / w v)$ neurons with elongated normal $(+/+)$ astroglial processes in vitro. After 48 hr in vitro, the cultures were immunostained with AbGFP to visualize astroglial cells and their processes. Weaver neurons fail to form appositions characteristic of migrating cells on normal astroglial cell processes. Instead, the weaver neuron $(N)$ binds to the glial processes by the terminal of one of its processes. A growth cone $(g c)$ is seen on the ending of the other neurite. When co-cultured with weaver neurons, normal astroglial cells are less differentiated, having thickened arms and flattened terminal endings (arrows). $G$, Glial cell soma. Video-enhanced Nomarski optics image made by the method of Allen et al. (1981). Photographs were taken from the video monitor as described by Hatten and Liem (1981). $\times 550$.

that of normal neurons (Table 1), but higher than that of weaver neurons recombined with weaver glia. Although this represented a marked improvement in weaver granule neuron survival as compared with mixed cultures of weaver granule neurons and astroglia (Hatten et al., 1984b), even in the presence of normal astroglia, a significant loss of weaver granule neurons occurred. As reported previously (Hatten et al., 1984b), weaver neurons tended to have a high background when immunostained with 

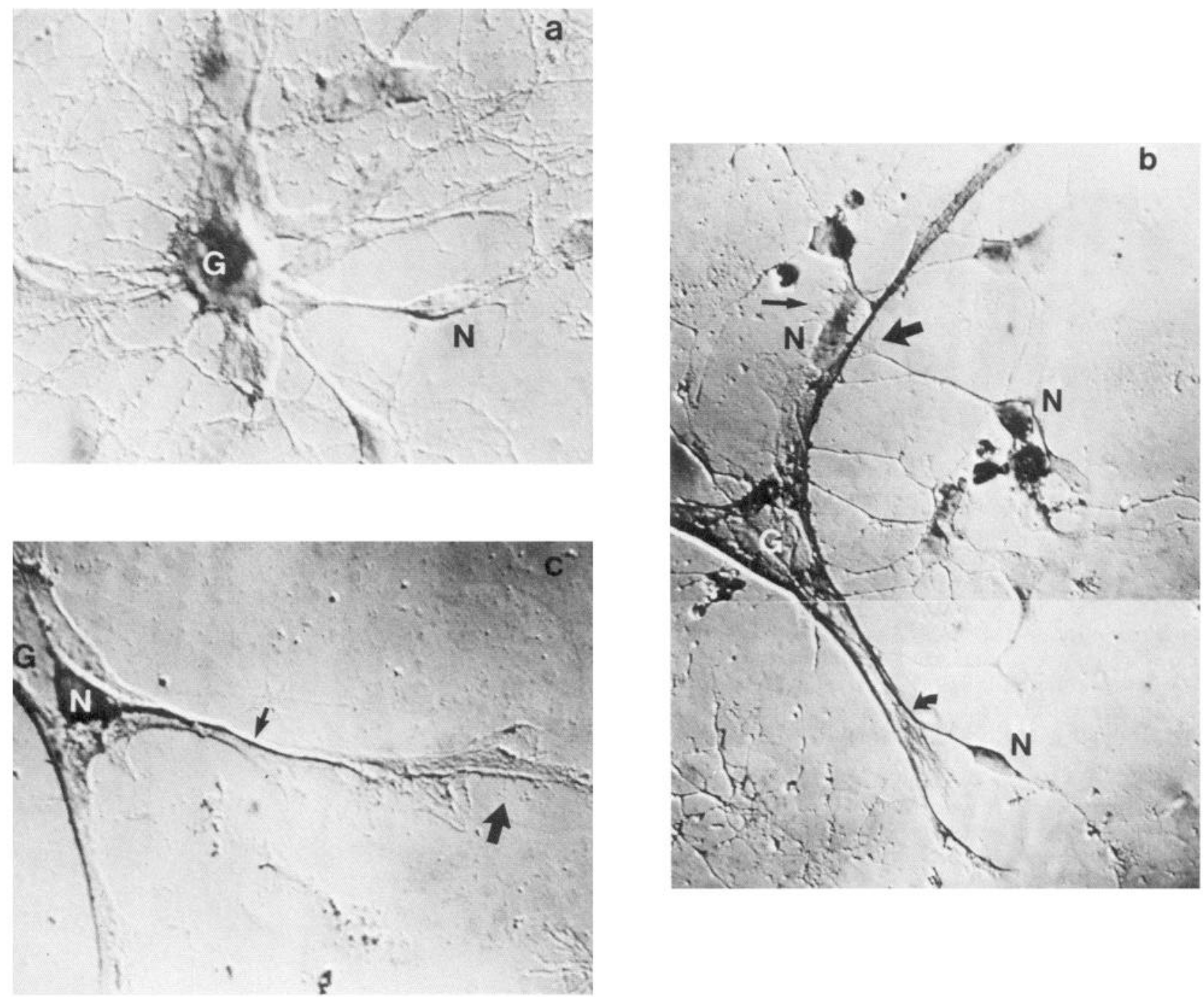

Figure 2. Interaction of normal $(+/+)$ and weaver $(w v / w v)$ neurons with stellate astroglial forms of the opposite genotype. a, Normal $(+/+)$ granule neurons were recombined with weaver $(w v / w v)$ astroglia at plating. After $48 \mathrm{hr}$ in vitro, the cultures were stained with AbGFP by the PAP method. In the presence of normal granule neurons, weaver astroglial cells differentiate more fully into both stellate and elongated forms. Here a stellate form $(G)$ harbors 12 or more neurons among its processes. Neurons $(N)$ are in a plane of focus above the stained astroglial cell $(G)$. $b$ and $c$, Weaver $(w v / w v)$ neurons were recombined with normal $(+/+)$ astroglia at plating. After $48 \mathrm{hr}$ in vitro, the cultures were stained with AbGFP by the PAP method. Normal astroglia $(G)$ are less differentiated in the presence of weaver neurons, having a more flattened form and bearing fewer processes. Most weaver neurons $(N)$ keep their distance from astroglial cells $(G)$, generally contacting them by the terminals of their processes $($ thick arrow, $b$ ); some extend neurites along the glial arm (curved arrow, b). One neuron binds to the glial arm, but fails to extend a perikaryal "leading process" (thin arrow, $b$ ). Other neurons $(N)$ position their cell bodies on astroglial cell bodies $(G)$ and track their neurites out along the astroglial arms. Microscopy and photography as described in Figure $1 . \times 500$.

AbGFP. In companion cultures, we immunostained with AbNILE to confirm the neuronal character of the cells.

Second, normal astroglia were less differentiated morphologically when they were co-cultured with weaver neurons (Figs. $1,2)$. Many normal astroglial cells that were co-cultured with weaver neurons had enlarged cell bodies with shorter and thicker processes, terminating in flattened endings, than those of normal astroglia co-cultured with normal neurons (Figs. 1;2, b,c). This result was unchanged when the number of surviving granule neurons was brought to a neuron : glial ratio of $4: 1$ by increasing the number of weaver neurons added at plating.

The third and most notable feature of weaver neurons cocultured with normal glia was that although the vast majority of weaver granule neurons were located near the astroglia, close appositions of the sort seen for migrating neurons were not seen (Fig. 1, Table 2). Instead, weaver neurons kept their distance from normal astroglia, often contacting them only at the tip of a short process (Figs. 1, 2).

The most striking case studied was the recombination of normal neurons with weaver astroglia. The survival rate of normal neurons increased slightly in the presence of weaver astroglia (Table 1). Normal granule neurons associated with weaver astroglia (Fig. 2a) and more than 600 normal neurons seen on elongated astroglial arms in each microculture had the morphological characteristics of migrating cells (Fig. 3, Table 2). Most significantly, instead of a flattened, stunted shape (Hatten et al., 1984b), weaver astroglia had shapes that more closely resembled those of wild-type astroglia seen in vivo, which have more numerous processes with more tapered endings when they were co-cultured with normal neurons (Figs. $2 a, 3$ ). Both elongated and stellate astroglial forms were seen in the presence of normal neurons. As has been reported for cultures of normal 
Table 1. Survival of normal $(+/+)$ and weaver $(w v / w v)$ granule neurons in recombination cultures

Genotype of cells

\begin{tabular}{lcc} 
Neurons & Astroglia & $\begin{array}{c}\text { Neurons } \\
\text { surviving (\%) }\end{array}$ \\
\hline$+/+$ & $+/+$ & 100 \\
$w v / w v$ & $+/+$ & $22 \pm 5$ \\
$+/+$ & $w v / w v$ & $108 \pm 6$ \\
$w v / w v$ & $w v / w v$ & $3 \pm 1$
\end{tabular}

Neurons and glia were plated in microcultures at an initial ratio of $4: 1$. The tota number of cells was $2-5 \times 10^{5}$ per culture. After $48 \mathrm{hr}$, the cultures were immunostained with AbGFP or with antisera raised against the NILE glycoprotein, and the total number of neurons per culture was scored. For cultures of normal neurons recombined with normal astroglia, cell viability, as measured by trypan blue uptake, was $85-95 \%$. The number of neurons in this culture is given as $100 \%$. For other recombinations, the number of neurons represents the mean count for 10 fields divided by the same count for a $(+/+) /(+/+)$ culture. Results are averaged from 5 experiments.

postnatal cerebellar cells (Hatten et al., 1984a), 10-20\% of the weaver astroglia co-cultured with normal neurons were highly elongated (Fig. 3) and resembled Bergmann cells (Hatten et al., 1984a).

To quantitate the interaction of normal or weaver neurons with astroglia of the same or other genotype, we measured the distance of unstained neurons from AbGFP-positive glial processes (Hatten and Liem, 1981). As with microcultures of early postnatal cerebellar cells taken from $\mathrm{C} 57 \mathrm{Bl} / 6 \mathrm{~J}$ mice and cultured for $48 \mathrm{hr}$, the vast majority of normal neurons were within 10 $\mu \mathrm{m}$ of normal astroglial arms (Fig. 4). A very similar result was seen when normal neurons were recombined with weaver astroglial cells. By contrast, the distibution of weaver neurons on either weaver or normal astroglial arms was more random. Thus normal neurons associated with either normal or weaver astroglial processes, whereas weaver neurons failed to do so.

To quantitate the number of migrating neurons among the cells that were close to a glial arm (Fig. 4), we counted the neurons that tightly apposed their cell soma to, and extended a leading process (i.e., a "migrating neuron") along, an AbGFPstained glial process (Table 2 ). Although a few migrating weaver neurons were seen when weaver cells were plated on normal astroglia, this number was several hundredfold less than that seen when normal neurons were mixed with weaver astroglial cells.

A finding not explained by the present analysis was that when normal neurons were co-cultured with weaver astroglia, an unusually large number of migrating neurons was seen. This result was repeated with each of the 14 animals studied.

After $48-72 \mathrm{hr}$ in vitro, the number of elongated astroglial cells and their associated migrating neurons declined, both in recombinations of normal neurons with weaver astroglia and

Figure 3. Interaction of normal $(+/+)$ granule neurons with weaver $(w v / w v)$ astroglial processes in vitro. Normal neurons were recombined with weaver astroglia at plating as described. After $48 \mathrm{hr}$, the cultures were immunostained with AbGFP to identify astroglia and their processes. Many normal neurons assume the posture of migrating neurons on weaver astroglial cell arms. A single elongated astroglial cell is shown with its cell body $(G)$ at the lower portion of the field. Six migrating neurons $\left(N_{1}-N_{6}\right)$, each with an elongated cell body tightly apposed to the glial process and a leading process out along the glial arm, are seen along the glial process, each in different aspects of migration. In the upper portion, an unstained neuron $\left(N_{l}\right)$ is attaching its terminal to the stained endfoot (arrow) of the glial process. The second migrating neuron resembles an "inchworm" $\left(N_{2}\right)$, the third extends a neurite away from the glial arm $\left(N_{3}\right)$, the fourth drapes its cell soma and leading process over the edge of the glial arm $\left(N_{4}\right)$ as it appears to spiral down the

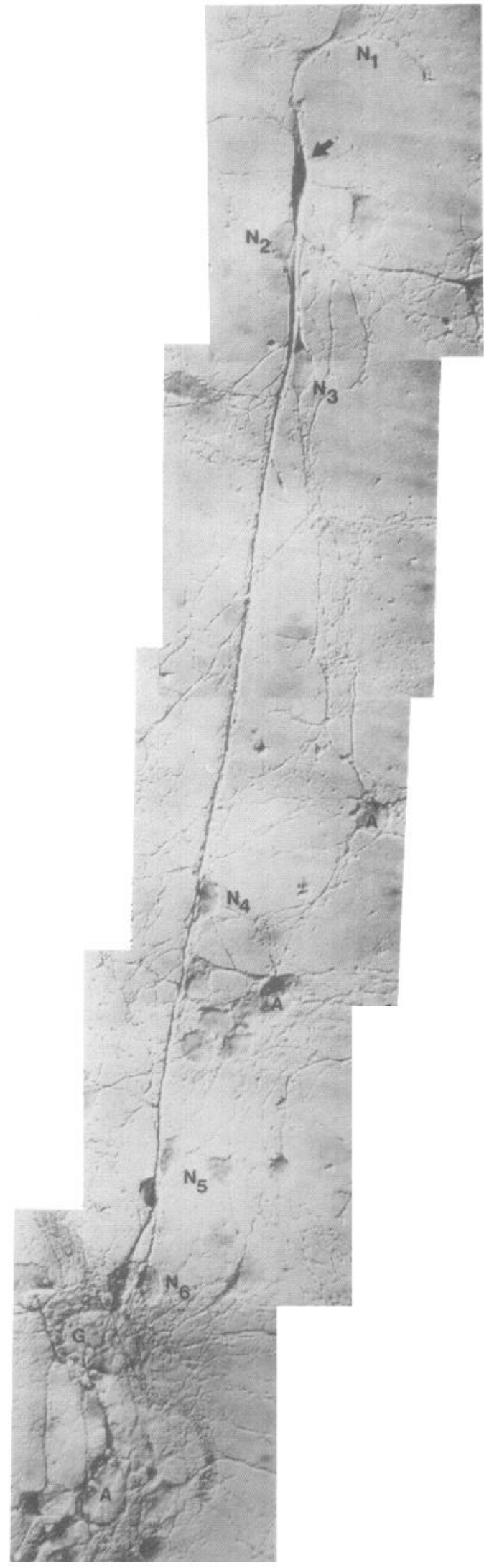

process. Adjacent to the cell body of this stained glial cell is a second glial cell, a stellate glial form $(A)$. A number of unstained neurons, possibly having come off of the elongated glial arms, are seen among its processes. Microscopy and photography as described for Figure 1. $\times 820$. 


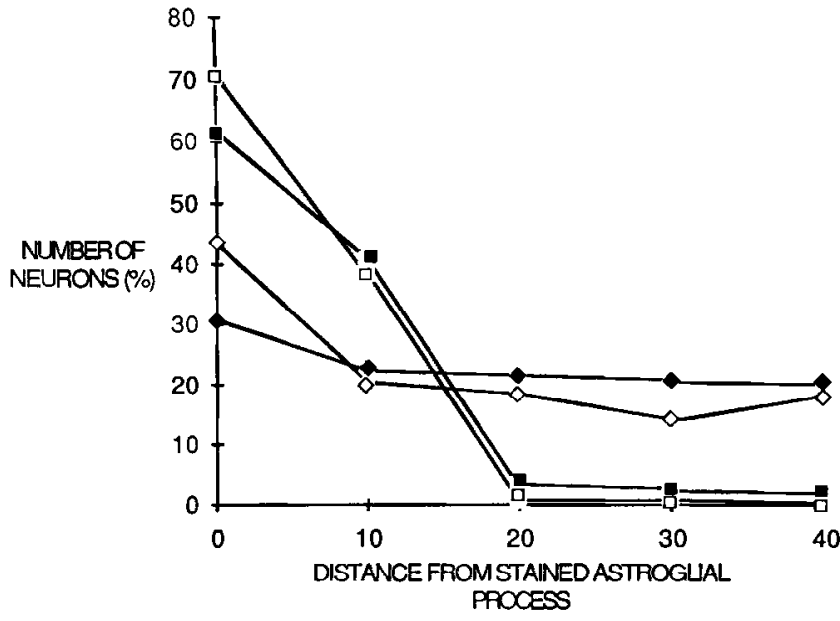

Figure 4. Distribution of weaver $(w v / w v)$ and normal $(+/+)$ granule neurons with weaver $(w v / w v)$ and normal $(+/+)$ astroglia. To quantitate the interaction of normal or weaver neurons with astroglia of the same or other genotype, we stained recombination cultures with AbGFP after $48 \mathrm{hr}$ in vitro and measured the distance of unstained neurons from AbGFP $(+)$ glial processes (for details, see Hatten and Liem, 1981). The total number of neurons at a given distance $(\mu \mathrm{m})$ from a stained glial process is given. Normal neurons along normal astroglia ( $\square$ ); normal neurons along weaver astroglia ( $(\mathbb{1})$; weaver neurons along normal astroglia $(\diamond)$; and weaver neurons along weaver astroglia $(\diamond)$.

\begin{tabular}{|c|c|c|}
\hline \multicolumn{2}{|c|}{ Genotype of cells } & \multirow{2}{*}{$\begin{array}{l}\text { No. of migrating } \\
\text { neurons }\end{array}$} \\
\hline Neurons & Astroglia & \\
\hline$+/+$ & $+/ t$ & 329 \\
\hline$w v / w v$ & $w v / w v$ & 6 \\
\hline$+1+$ & $w v / w v$ & 628 \\
\hline$w v / w v$ & $+/ t$ & 28 \\
\hline
\end{tabular}

Neurons and astroglia were recombined at a ratio of 4:1 immediately after the separation procedure. After $48 \mathrm{hr}$ in vitro, the cells were immunostained with AbGFP to visualize glial cells and their processes; astroglial cells with elongated processes $(100 \mu \mathrm{m}$ or longer) were examined for the presence of migrating neurons. Neurons that tightly apposed their cell somata to, and extended a leading process along, an AbGFP-stained process were scored as migrating cells from a single experiment, each culture having the same starting number of astroglial cells.

in those of normal neurons with normal astroglia. This is in agreement with our previous findings that migration occurs in microcultures for only a few days after plating (Hatten et al., 1984a), and with studies of Trenkner et al. (1985) on neuronal migration in reaggregate cultures.

\section{Discussion}

These experiments suggest that normal neurons can associate with either normal or weaver astroglia in vitro and that they can form neuron-glia relationships typical of migrating neurons on either normal or weaver astroglia. By contrast, weaver neu-
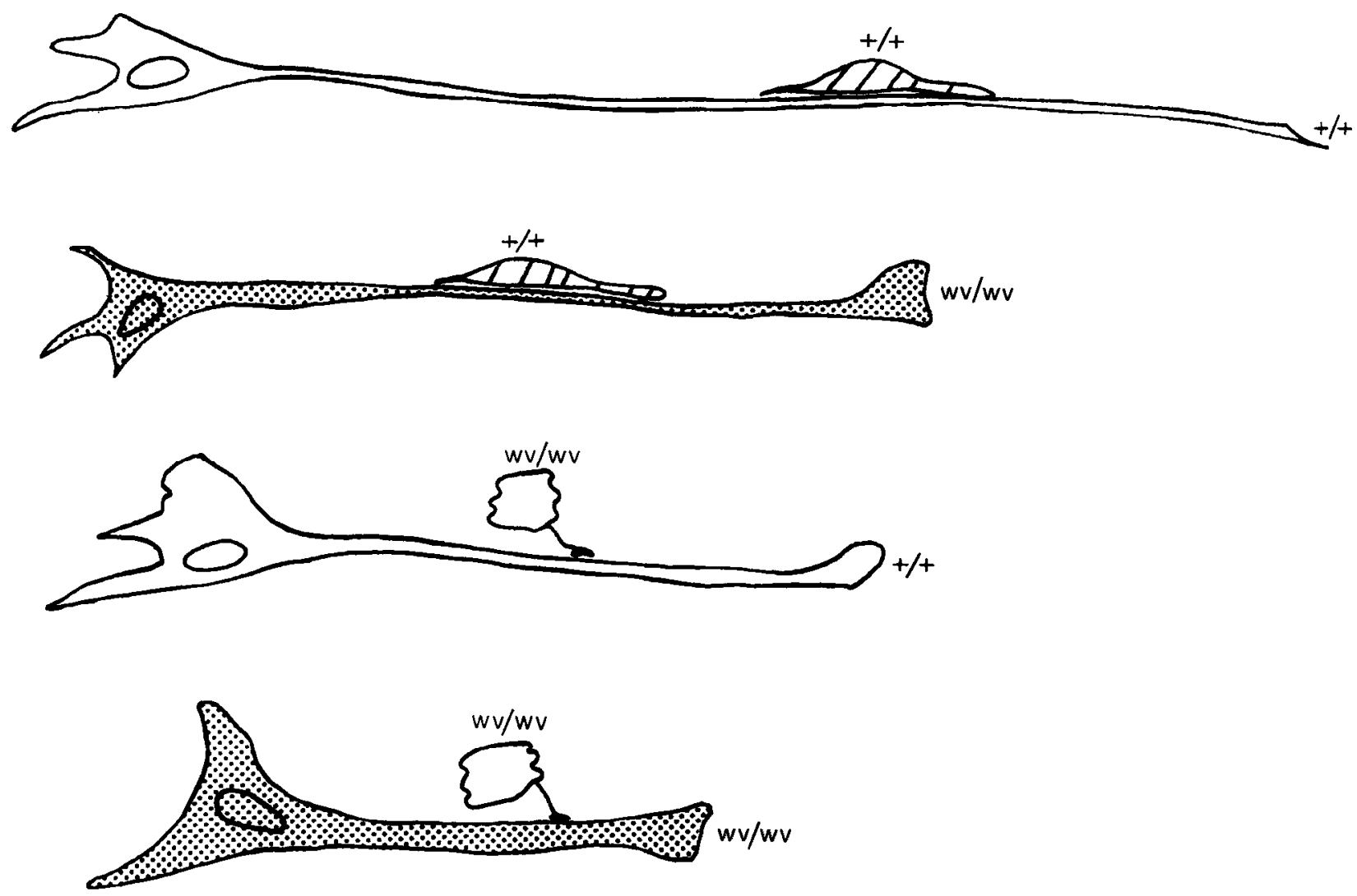

Figure 5. Model for defects in weaver ( $w v / w v)$ neuron-glial interactions. Normal neurons form appositions typical of migrating cells on either normal or weaver astroglia. Weaver neurons fail to migrate on either type of astroglial cell. In all cases, astroglial morphological differentiation is enhanced by the presence of normal neurons and impaired by weaver neurons. 
rons keep their distance from both normal and weaver astroglia and fail to form migration appositions.

These results also underscore the importance of neuron-glia interactions to the morphological differentiation of astroglia. Normal neurons induce the morphological differentiation of normal astroglia in vitro into forms resembling those seen in vivo (Hatten, 1985), and induce weaver astroglia to extend more numerous processes that are more elongated and slender than those of weaver astroglia co-cultured with weaver neurons (Fig. 5). However, weaver astroglia, even when co-cultured with normal neurons, fail to form shapes as complex or processes as elongated as do normal astroglia co-cultured with normal neurons. Thus, weaver neurons fail to induce the complete morphological differentiation of cither normal or weaver astroglia in vitro.

Recent work on dissociated cell cultures from normal mouse cerebellum suggests that neuron-glia contacts are needed for neuronal regulation of astroglial shape, and that elements of the neuronal plasma membrane and not trophic factors are involved in this interaction (Hatten et al., 1985). Although the molecular mechanism of neuronal induction of glial differentiation is not yet understood for either normal or weaver cells, these experiments point out the striking influence of granule neurons on astroglial form.

The weaver defect, therefore, leads to a cascade of events that involves a failure of both neuronal and astroglial differentiation (Fig. 5). Weaver neurons fail to bind to Bergmann glia and to induce them to make the specialized, elongated processes that appear to support neuronal migration in normal animals (Rakic and Sidman, 1973a, b). Consequently granule cell migration fails, neurite extension is impaired, and many ectopic granule neurons die. Thus, the present study supports the suggestion of Sotelo and Changeaux (1974) and Goldowitz and Mullen (1982) that the granule neuron is a primary site of action of the weaver gene.

The finding that weaver granule neurons do not bind to either normal or weaver astroglial cells suggests that the defect is in the granule neuron membrane molecules involved in neuronglia interactions. This interpretation is consistent with our previous finding that postnatal weaver granule neurons maintain embryonic cell-surface characteristics (Hatten et al., 1984b). Thus it is possible that the weaver neuron has a cell-surface defect that prevents glial contacts needed, first, for astroglia to project oriented, elongated processes and, subsequently, for the neurons to migrate on those processes.

The influence of neurons on glial differentiation is most likely mediated by cell-cell interactions at the membrane level. A major question is, What molecules within the membrane mediate this glial reaction? In recent work, we have used the microculture system as an assay for immune sera that disrupt neuron-glia relationships in cultures of dissociated cerebellum. One polyclonal antiserum, raised in rabbits against whole cerebellar cells, concomitantly blocks neuronal associations with astroglia and induces flattened glial forms with stunted processes. The antigen that mediates the blocking activity of this immune serum is a glycoprotein present on granule neurons, but not on PC12 cell membranes (Edmondson et al., 1985). Other antisera raised against the neuronal antigens NILE (Salton et al., 1983), L1 (Lindner et al., 1985), Ng-CAM (Grumet and Edelman, 1984), BSP-2 (Langley et al., 1983), and N-CAM (Thiery et al., 1977) do not disrupt neuron-glia relationships, block neuronal migration or affect astroglial morphology in this microculture system (Edmondson et al., 1985). Since gliophilic neuronal migration in other regions of the developing weaver mouse brain is normal (Caviness and Rakic, 1978), it will be of interest to determine whether neuron-glia interaction molecules are distinct in different brain regions.

In vitro recombination of mutant and normal cells in micro- cultures allows a controlled mixing of neurons and astroglia with a particular genotype. It thus offers promise for a detailed analysis of gene action in cell-cell relationships, including behaviors as complex as neuronal migration in developing brain, and provides a new technique with which to carry out molecular biological studies on granule neurons or astroglia from animals of a particular genetic background. For weaver, it should now be possible to use this in vitro system to directly assay which surface antigens are missing on weaver granule neurons and whether these or other molecules regulate astroglial differentiation.

\section{References}

Allen, R. D., N. S. Allen, and J. L. Travis (1981) Video-enhanced contrast polarization (AVEC-POL) microscopy: A new method applied to the detection of birefringence in the reticulopodial network of Allogromia ratiocollaris. Cell Motil. 1: 291-302.

Bignami, A., and D. Dahl (1974) The development of Bergmann glia in mutant mice with cerebellar malformations: Reeler, staggerer and weaver. Immunofluorescence study with antibodies to the glial fibrillary acidic protein. J. Comp. Neurol. 155: 219-230.

Caviness, V. S., Jr., and P. Rakic (1978) Mechanisms of cortical development: A view from mutations in mice. Annu. Rev. Neurosci. I: 297-326.

Edmondson, J. C., J. M. Alter, and M. E. Hatten (1985) Characterization of a polyspecific antiserum that disrupts neuron-glial interactions in vitro. Soc. Neurosci. Abstr. 11:1137.

Goldowitz, D., and R. J. Mullen (1982) Granule cell as a site of gene action in the weaver mouse cerebellum: Evidence from heterozygous mutant chimeras. J. Neurosci. 2: 1474-1485.

Grumet, M., and G. M. Edelman (1984) Heterotypic binding between neuronal membrane vesicles and glial cells is mediated by a specific cell adhesion molecule. J. Cell Biol. 98: 1746-1756.

Hatten, M. E. (1984) Embryonic cerebellar astroglia in vitro. Dev. Brain Res. 13: 309-313.

Hatten, M. E. (1985) Neuronal regulation of astroglial morphology and proliferation in vitro. J. Cell Biol. 100: 384-396.

Hatten, M. E., and A. M. Francois (1981) Cell assembly patterns of developing cerebellar cells on lectin-derivatized culture substrata. Dev. Biol. 87: 102-113.

Hatten, M. E., and R. K. H. Liem (1981) Astroglial cells provide a template for the positioning of developing cerebellar neurons in vitro. J. Cell Biol. 90: 622-630

Hatten, M. E., and R. L. Sidman (1978) Cell reassociation behavior and lectin-induced agglutination of embryonic mouse cells from different brain regions. Exp. Cell Res. 113: 111-125.

Hatten, M. E., R. K. H. Liem, and C. A. Mason (1984a) Two forms of cerebellar glial cells interact differently with neurons in vitro. J. Cell Biol. 98: 193-204.

Hatten, M. E., R. K. H. Liem, and C. A. Mason (1984b) Defects in specific associations between astroglia and neurons occur in microcultures of weaver mouse cerebellar cells. J. Neurosci. 4: 1163-1172.

Hatten, M. E., M. Woods, J. Sanchez, C. A. Mason, and R. K. H. Liem (1985) Neuron-glial contacts induce astroglial morphological differentiation. Soc. Neurosci. Abstr. 11: 984.

Langley, O. K., G. Gombos, M. Hirn, and C. Goridis (1983) Distribution of the neural antigen BSP-2 in the cerebellum during development. J. Dev. Neurosci. 1: 393-401.

Liem, R. K. H., S.-H. Yen, G. D. Salomon, and M. L. Shelanski (1978) Intermediate filaments in nervous tissue. J. Cell Biol. 28: 637-645.

Lindner, J., F. G. Rathjen, and M. Schachner (1985) L1 mono- and polyclonal antibodies modify cell migration in early postnatal mouse cerebellum. Nature 305: 427-430.

Rakic, P. (1971) Neuron-glia relationship during granule cell migration in developing cerebellar cortex: A Golgi and electron microscopic study in Macacus rhesus. J. Comp. Neurol. 141: 282-312.

Rakic, P., and R. L. Sidman (1973a) Sequence of developmental abnormalities leading to granule cell deficit in cerebellar cortex of weaver mutant mice. J. Comp. Neurol. 152: 103-132.

Rakic, P., and R. L. Sidman (1973b) Weaver mutant mouse cerebellum: Defective neuronal migration secondary to abnormality of Bergmann glia. Proc. Natl. Acad. Sci. USA 70: 240-244.

Rakic, P., L. J. Stensaas, E. P. Sayre, and R. L. Sidman (1974) Computer-aided three dimensional reconstruction and quantitative anal- 
ysis of cells from serial electron microscopic montages of foetal monkey brain. Nature 250: 31-34.

Rezai, Z, and H. Yoon (1972) Abnormal rate of granule cell migration in the cerebellum of "weaver" mutant mice. Dev. Biol. 29: 17-26.

Salton, S. R. J., C. Richter-Landsburg, L. A. Greene, and M. L. Shelanski (1983) Nerve growth factor-inducible large external (NILE) glycoprotein: Studies of a central and peripheral neuronal marker. J. Neurosci. 3: 441-454.

Sidman, R. L., and P. Rakic (1978) Neuronal migration, with special reference to developing human brain. A review. Brain Res. 62:1-35. Sotelo, C., and P. Changeaux (1974) Bergmann fibers and granule cell migration in the cerebellum of homozygous weaver mutant mouse. Brain Res. 77: 484-494.

Thiery J.-P., R. Brackenbury, U. Rutishauser, and G. M. Edelman (1977) Adhesion among neural cells of the chick embryo. II. Purification and characterization of a cell adhesion molecule from neural retina. J. Biol. Chem. 252: 6841-6845.

Trenkner, E., D. Smith, and N. Segil (1985) Is cerebellar granule cell migration regulated by an internal clock? J. Neurosci. 4: 2850-2855.

Willinger, M., and D. M. Margolis (1985) Effect of the weaver (wv) mutation on cerebellar neuron differentiation. I. Qualitative observations of neuron behavior in culture. Dev. Biol. 107: 156-172. 